\title{
Distinguishing familiarity from list search responses in a reaction time task*
}

\author{
ARNOLD L. GLASS \\ Stanford University, Stanford, California 94305 \\ JULIA COX $\dagger$ \\ University of Washington, Seattle, Washington 98105 \\ and \\ SUSAN J. LeVINE \\ Indiana University, Bloomington, Indiana 47401
}

\begin{abstract}
This experiment tested the claim of the model proposed by Atkinson and Juola (in press) that recognition responses in an RT task are a mix ture of fast responses on the basis of the item's familiarity and slower responses based on a list search for the item. All Ss had to learn two 16-word lists (A and B). Then they had to respond alternately to "Is the following a List A word?" and "Is the following a List B word?" In the control task, the members of one list served as distractors for the other. Hence, the familiarity values of the targets and distractors were equal, and the only basis for response was a list search. In the experimental task, the distractors were not list words. Hence their familiarity was lower, and familiarity responses could be made. There were no differences between two groups of Ss when they all responded in the control task. But when half the Ss were switched to the experimental task, they responded significantly faster than the Ss who continued in the control task. In the experimental task, distractors were rejected quicker than targets were identified, but in the control task, the reverse was true. These results support the hypothesis that the control task required a list search while a familiarity judgment was possible in the experimental task.
\end{abstract}

Tulving (1972) has pointed to an intuitive difference between knowledge of facts (e.g., that George Washington was the first President of the U.S.) and knowledge of events (e.g., what one was doing $5 \mathrm{~min}$ ago). He referred to these two kinds of memories as semantic and episodic.

Atkinson and Juola (in press) incorporated this distinction in somewhat different form in a model of recognition memory. They viewed long-term memory as being partitioned into a lexical store and an event-knowledge store. The lexical store maintains a set of symbols and codes that can be used by the $S$ to represent the occurrence of particular events. The acquisition of a list of words involves increasing the familiarity of list items in the lexical store. The familiarity value for a word is a function of the time since that word was last accessed and the number of times the word has been accessed in the past. In addition, the code or codes that represent a word in the

*We thank K. Flanagan, S. Loeb, and C. Vasil for running Ss, G. Balzano for his help with the statistics, and R. Atkinson, G. Bower, K. Holyoak, and E. Smith for commenting on various versions of this paper. $K$. Wescourt made helpful suggestions at various stages of the experiment, most notably in successfully predicting and explaining the results before it was even begun. While this study was conducted, the first author held an N.S.F. graduate fellowship. This research was supported by Grant MN13950-06 from the National Institute of Mental Health to Gordon H. Bower, and is also sponsored by Bower, who takes full editorial responsibility for its contents.

†Now at Indiana University, Blooming ton, Indiana 47401. lexical store are copied and placed in the event-knowledge store.

The Atkinson and Juola model assumes that when a test stimulus is presented, the $\mathrm{S}$ accesses the lexical store and retrieves the familiarity value for the stimulus. Response decisions based only on this familiarity value can be made quickly. If the familiarity value is very high, indicating the word has been accessed recently, a positive response is made. If the familiarity value is very low, indicating the word has not been accessed recently, a negative response is made. If the familiarity value is neither very high nor very low, a search of the event-knowledge store is executed. This latter search process guarantees that the $\mathrm{S}$ will arrive at a correct decision, but with a consequent increase in response latency.

The Atkinson and Juola analysis of a recognition task thus suggests that there are two kinds of responses: quick responses based on familiarity judgments and slow responses based on an extended search of the event-knowledge store. This predicts a bimodal distribution of reaction times. However, bimodality is difficult to test for statistically, and, consequently, such a test has not been made. However, the theory might be tested by designing a task where Ss could only respond on the basis of a search of the event-knowledge store. RT should be slower in this task than on a second task in which responses on the basis of familiarity are possible. The present experiment compared decision RTs for two such tasks. 
For the following experiment, a $\mathrm{S} \cdot$ first had to learn two 16-word lists, List A and List B. After both lists had been learned to criterion, the $\mathrm{S}$ was given an RT task. On alternate trials the $\mathrm{S}$ was asked, "Is the following a List A word?" and "Is the following a List B word?" List B words served as distractors for List A, and vice versa. Since the same words served as both list words and distractors, the familiarity values of the list words and distractors was the same. According to the Atkinson and Juola model, every response would, therefore, have to be made on the basis of an extended search of the event-knowledge store. Ss were run on this task until each list item had been presented six times.

The task was then changed so that, on every trial, either a list word or a distractor which the $S$ had never seen before was presented. In this task, according to Atkinson and Juola, the $S$ snould have been able to respond quickly on the basis of the familiarity of the list words without an extended search of the event-knowledge store. Consequently, RT should decrease considerably. This group of experimental Ss was compared to a control group which continued to perform the original task. When both target and distractor items are list members for both groups, there should be no differences in the performances of the experimental and control groups. But if the familiarity hypothesis is correct, the experimental group should be able to respond significantly faster than the control group when its distractors are switched to nonlist items.

The Ss in the experimental group were run on the second task until they had seen each distractor three times. Then a new set of distractors was introduced. According to Atkinson and Juola, the familiarity value of the old distractors should have been increasing with each presentation. Therefore, it should have been getting increasingly difficult to reject them as unfamiliar. Since the new distractors would then have lower familiarity values than the old distractors, RT to reject the new distractors should be faster.

\section{METHOD}

\section{Materials}

Fifty-six high-imagery words with Thorndike-Lorge frequencies of over 50 per million were selected from the Paivio, Yuille, and Madigan (1968) word norms and divided into two 16 -word lists (A and B) and a pool of 24 distractors.

\section{Procedure}

Twenty-four Stanford undergraduates were paid $\$ 5$ each for participating in the experiment. Each $S$ was given copies of List A and List B to memorize prior to the RT experiment. At the beginning of the experimental session, the $S$ was asked to repeat each list fluently and without error on the first try; if he succeeded, he was allowed to perform the RT task. In the RT task, the $S$ had to respond whether a tachistoscopically presented word was a member of the appropriate list by pressing a "yes" button if it was on the list and "no" button if it was not. On alternate trials, the $\mathbf{S}$ was asked "Is the following a List $\mathbf{A}$ word?" and "Is the following a List B word?" Each S was given 2 practice blocks and 8 test blocks for a total of 10 blocks of 32 trials each. For 12 pairs of Ss in the experimental and control conditions, the stimuli presented in the first 6 blocks (P1-2 and
1-4) of trials were identical. Half of List A and half of List B were presented as positive items (targets), while the other halves of the lists were used as negative items (distractors). Thus, List A items were distractors for List B and List B items were distractors for List A. All items were presented equally of ten as targets and distractors.

On Blocks 5-8, both the control and experimental groups continued to make positive responses if a List $\mathbf{A}$ word (on alternate trials, a List B word) was presented. For the control group, the nature of the distractors for Blocks 5-8 was the same as for the first six blocks. However, for the experimental group, words which the $S$ had not memorized as part of a list were used as distractors for the last four blocks. For Blocks 5-7, the same set of new distractors were used. The same distractors were thus seen three times. On the last block, half (eight) of the distractors were shown for the fourth time while half (eight) of the distractors shown had never been presented before.

Word presentation order was randomized within each block. The assignment of responses to the left or right hand was counterbalanced across Ss.

\section{RESULTS}

The first two blocks presented to each $\mathrm{S}$ were considered to be practice blocks, and the data from them were not analyzed. For the remaining eight blocks, any response that took longer than $2,500 \mathrm{msec}$ was counted as an error. The error rate for the experiment was $7 \%$, and across conditions error rate was correlated with RT. Prior to analysis of variance, errors were replaced by the S's mean RT for that condition. Both items and Ss were treated as random effects in all analyses reported in this paper, using methods outlined by Clark (1973).

The RT results for Blocks 5-8 are shown in Fig. 1. The prediction of the Atkinson and Juola model was that there should be a significant decrease in RT between Blocks 4 and 5 for the experimental group and no such decrease for the control group. However, this prediction is confounded with an overall main effect of practice that resulted in successive blocks being responded to more quickly for the experimental and control groups. The actual prediction of the Atkinson and Juola model, therefore, is that the difference between the experimental and control groups should be greater for Blocks 5-8 than for Blocks 1-4. An orthogonal comparison revealed that this difference was in fact significant $\left[F^{\prime}(1,201)=16.7, p<.001\right]$.

The second prediction of the model was that for the experimental group, on Block 8 , distractors that were presented for the first time should be rejected more quickly than distractors presented for the fourth time. Contrary to the prediction, distractors presented for the fourth time were rejected nonsignificantly more rapidly than distractors seen only once ( 587 vs $610 \mathrm{msec}$ ).

For Blocks 5-8, the experimental group made negative responses more quickly than positive ones, while the control group made positive responses more quickly than negative ones. Both groups made positive responses more quickly for the first four blocks. This interaction between group, block, and response type was significant $\left[\mathrm{F}^{\prime}(1,201)=9.25, \mathrm{p}<.005\right]$ when tested by an orthogonal contrast. 


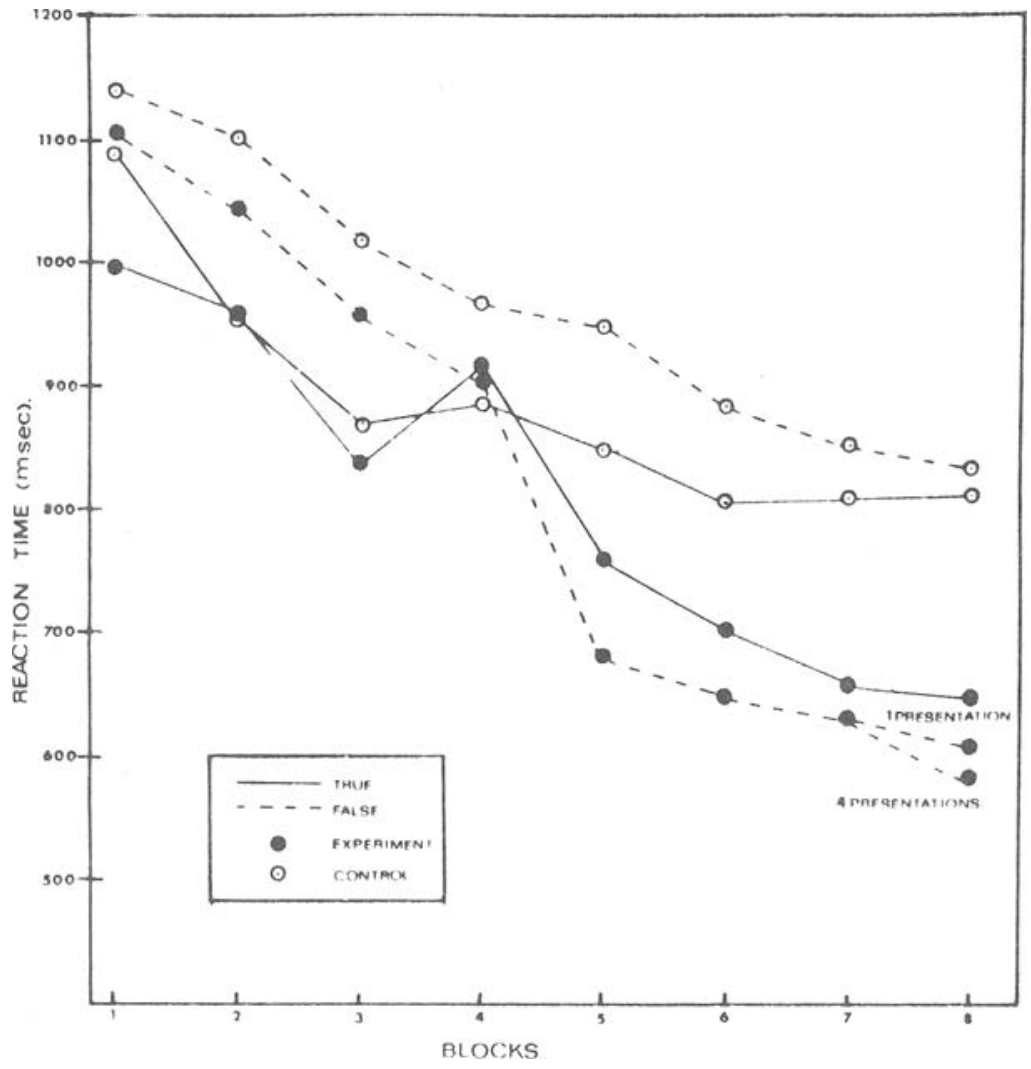

Fig. 1. Positive and negative reaction times for the control and experimental groups for Blocks 1-8.

\section{DISCUSSION}

In this experiment, it was easier to identify list words when the distractors were unfamiliar words than when the distractors were part of another list. This indicates that one can retrieve information that indicates a word is on some list faster than one can retrieve information that indicates which list a word is on. The critical question is: what exactly is the nature of such information?

If the test word presented is compared holistically to each of the list words either in parallel or by a self-terminating search, it will take longer on the average to reject a distractor than to identify a list member (Egeth, 1966). The finding that for all eight blocks the control group rejected distractors more slowly than it identified targets, and for the first four blocks the experimental group did the same, indicates that a list search model is appropriate for describing the behavior of these groups during these blocks. This result supports the hypothesis that the dual list learning and testing procedure employed would force Ss to employ list searches in order to perform the task. However, on Blocks 5-8 the experimental Ss rejected distractors more quickly than they identified targets. This provides strong evidence that Ss were using a decision procedure qualitatively different from a list search on these blocks.

This result can easily be accommodated by the Atkinson and Juola model. The more often the unfamiliar distractors fall below the criterion for low familiarity, the more often quick familiarity judgments rather than slow list search responses will be made. Similarly, the more of ten that the target words exceed the high familiarity criterion, the more often quick familiarity responses will be made for them. In order to explain why the mean RT for the distractors is lower, it is only necessary to assume that a greater percentage of responses are made on the basis of familiarity for distractors than for list items. In the context of the present experiment, the new distractors, presented for the first time after six blocks (including practice) of trials, would have uniformly low familiarity. However, it is not implausible to assume that some list items would have been learned better than others; the less well-learned list words might not always exceed the high familiarity criterion, and consequently would require a list search on some trials. Accordingly, it is not implausible to account for the present results by assuming that more quick familiarity judgments were made for distractors than for target items.

One finding of Atkinson and Juola (in press) failed to replicate in the present study. As the distractors are repeated, their familiarity should increase, and therefore they should exceed the low familiarity criterion less often. Consequently, they should have a longer mean RT than distractors which are being presented for the first time, and thus have lower familiarity values. Though Atkinson and Juola found this result, the difference was nonsignificantly in the opposite direction in the present study. In the Juola and Atkinson study, there were from 8 to 24 intervening items between repeated presentations of a distractor. In this study, approximately 32 items always intervened. It may be that the familiarity effects that Atkinson and Juola found are dissipated when many items intervene, and do not generalize to a situation when items are repeated only at long intervals.

The results of the present study suggest two interesting directions for future research. First, the results suggest that future experiments designed to discriminate between various list search models should use some procedure, such as the dual list-learning procedure desribed in this paper, to minimize the amount of responses due to familiarity. Second, while sophisticated versions of list search models have been described (Sternberg, 1969; Anderson \& Bower, 1973), no explicit mechanism has yet been described for recording and assessing familiarity. If familiarity judgments represent an alternative decision procedure qualitatively different from a list search, then the description of that procedure represents a new challenge to experimental psychologists. 


\section{REFERENCES}

Anderson, J. R., \& Bower, G. H. Human associative memory. Washington: Winston, 1973.

Atkinson, R. C., \& Juola, J. F. Search and decision processes in recognition memory. In D. H. Krantz, R. C. Atkinson, R. D. Luce, and P. Suppes (Eds.), Contemporary developments in mathematical psychology. San Francisco: Freeman, in press.

Clark, H. H. The language-as-fixed effect fallacy: A critique of language statistics in psychological research, Journal of Verbal Learning and Verbal Behavior, 1973, 12, 335-359.

Egeth, H. E. Parallel versus serial processes in multidimensional stimulus discrimination. Perception \& Psychophysics, 1966, 7 , 245-252.
Paivio, A., Yuille, J. C., \& Madigan, S. Concreteness, imagery, and meaningfulness values for 925 nouns. Journal of Experimental Psychology, 1968, 76(Monogr. Suppl. No. 1, Pt. 2).

Sternberg, S. The discovery of processing stages: Extensions of Donders' method. In W. G. Koster (Ed.), Attention and performance II. Amsterdam: North-Holland, 1969. Pp. 276-315.

Tulving, E. Episodic and sem antic memory. In E. Tulving and W. Donaldson (Eds.), Organization of memory. New York: Academic Press, 1972. Pp. 381-403.

(Received for publication May $3,1974$. 